"Saquen sus rosarios de nuestros ovarios": forma, contenido y disputa cultural en torno al aborto

Federico Juan Bauso Beltrán

https://perio.unlp.edu.ar/ojs/index.php/question/article/view/4870

Cita sugerida: Bauso Beltrán, F. (2018). "Saquen sus rosarios de nuestros ovarios": forma, contenido y disputa cultural

en torno al aborto. Question, 1(60), e109. doi:https://doi.org/10.24215/16696581e109

\title{
"Saquen sus rosarios de nuestros ovarios": forma, contenido y disputa cultural en torno al aborto
}

\author{
"Take out your rosaries from our ovaries": form, content and cultural \\ dispute about abortion
}

Federico Juan Bauso Beltrán fedebauso@gmail.com

http://orcid.org/0000-0002-1891-4068

Facultad de Ciencias Sociales; Universidad de Buenos Aires/

Universidad Nacional de las Artes (Argentina)

\section{Resumen}

Toda política pública se sitúa en un entramado de disputas por sus sentidos. Desde esta perspectiva, el artículo repone la puja de imaginarios culturales en relación con el aborto en el marco del debate parlamentario del proyecto de interrupción voluntaria del embarazo.

En este sentido, se plantea que el momento actual de institucionalización y conflicto del tema es heredero de dos procesos simultáneos: las manifestaciones del $\mathrm{Ni}$ Una Menos y la masificación del movimiento feminista argentino, por un lado, formateando la disputa; y el rol de la Campaña Nacional por el Aborto Legal, Seguro y Gratuito, por el otro, dando contenido, articulando argumentos y simbologías.

De esta forma, cobran relevancia los esfuerzos activistas por discutir lo naturalizado por el sentido común de una sociedad estructurada a partir del hecho patriarcal. 
Palabras clave: Aborto; feminismo; activismo; cultura.

\section{Abstract}

All public policy is placed in a web of disputes for its senses. From this perspective, the article replaces the bidding of cultural imaginaries in relation to abortion in the framework of the parliamentary debate of the project of voluntary interruption of pregnancy.

In this sense, it is stated that the current moment of institutionalization and conflict of the issue is the heir of two simultaneous processes: the manifestations of $\mathrm{Ni}$ Una Menos and the massification of the argentinian feminist movement, on the one hand, formatting the dispute; and the role of the National Campaign for Legal, Safe and Free Abortion, on the other, giving content, articulating arguments and symbols.

In this way, the activist efforts to discuss what is naturalized by the common sense of a society structured from the patriarchal fact become relevant.

Keywords: Abortion; feminism; activism; culture.

"Saquen sus rosarios de nuestros ovarios" es una consigna del feminismo que da cuenta de la injerencia de la Iglesia católica en el acceso a la salud sexual y reproductiva y, sobre todo, en el derecho al aborto legal de las personas con capacidad gestante (1). En este sentido, también, la interrupción voluntaria del embarazo se caracteriza como derecho a decidir, en una mayoría social y como crimen y asesinato, en sectores fundamentalmente religiosos y conservadores. Es decir, cada forma de nominar acarrea un enjambre de significaciones, valoraciones y pujas por el sentido.

En 2018, estas disputas irrumpieron en la agenda mediática argentina, a partir de la discusión en el parlamento sobre la despenalización y legalización del aborto, y atravesó estructuras sociales con formato de conflicto (2). A su vez, el avance del proceso legislativo se enmarca en la masificación y movilización del movimiento de mujeres en el país. Con el antecedente del NiUnaMenos, las manifestaciones posteriores, y la Campaña Nacional por el Derecho al Aborto Legal, Seguro y Gratuito, como repertorio (3) de prácticas de participación y contenido, y la institucionalización del fenómeno en el marco del debate parlamentario; la discusión en torno al proyecto de ley recrudeció (4). En este marco, como señalamos al comienzo, los ámbitos más 
conservadores del país, estructurados alrededor de la Iglesia católica, abordaron el tema desde argumentos morales y religiosos fundados en las mitologías propias de su credo. En este sentido, la filósofa y feminista Diana Maffía afirmó en plenarios de comisiones de la Cámara de Diputados de la Nación que:

\begin{abstract}
Los mismos que hoy argumentan en contra del derecho al aborto legal, estuvieron en contra del divorcio vincular, de la patria potestad compartida, de la educación sexual, del acceso a la anticoncepción, del matrimonio igualitario, siempre con argumentos tremendistas que fueron desmentidos por la sociedad, porque somos perfectamente capaces de hacer un uso racional de la ley. Esos segmentos de la sociedad que se autoatribuyen y ejercen con un poder de macho cruel una función de tutela sobre nosotras, nos sigue tratando como menores de edad perpetuas. Estamos aquí un siglo después y todavía se pretende que debemos demostrar que podemos tomar decisiones autónomas sobre nuestra vida (Maffía, 2018).
\end{abstract}

En medio de estas tensiones, y en el marco de su ilegalidad, se realizan en la Argentina aproximadamente 450.000 abortos por año (5) y las complicaciones de la situación de clandestinidad provocan que este proceso sea la primera causa de muerte individual en personas gestantes. En este sentido, nos interesa problematizar cómo un asunto de salud pública que, de ser legal, evitaría la muerte de mujeres concretas es discutido en nombre de abstracciones como el proyecto universitario de un niño por nacer o a partir de posicionamiento perversos como el de la diputada de Unidad Justicialista, Ivana Bianchi, quien denunció, en la Cámara Baja en el marco de la discusión por el proyecto de interrupción voluntaria del embarazo (IVE), el riesgo de tráfico de órganos de fetos (6). En el entramado de argumentaciones contra el aborto lo que se puede encontrar como núcleo común es que, como afirmó Maffía (2018), la dignidad que se le otorga a un embrión, "un ser en gestación potencialmente humano, se nos niega desde hace siglos a las mujeres. Se desconoce nuestra condición de sujetos morales, se obstruye nuestra autonomía y se debilita el reconocimiento de nuestra ciudadanía".

A partir de lo antedicho, y como venimos señalando, nos interesa reflexionar sobre los fenómenos culturales que se tejen alrededor de una política pública. En continuidad con lo planteado por Cris Shore (2010) nos proponemos realizar una aproximación antropológica al debate por el aborto. "Qué quiere decir" para las personas la IVE. Esto implica preguntarnos por los sentidos movilizados alrededor del proyecto de aborto y las implicaciones culturales que plantea a la sociedad. Como señala Shore: 
la política pública -tal como el poder- parece funcionar de manera más efectiva cuando sus mecanismos de operación son invisibles, cuando parece tan 'natural' que pasa desapercibida y sin cuestionar o cuando se proyecta en el inexpugnable lenguaje neutral de la 'ciencia' (2010: 45).

De esta forma, en el contexto de una sociedad patriarcal, que naturaliza los gestos de dominio, se hace evidente la primacía de las opiniones personales y morales sobre qué hacen las mujeres con sus cuerpos en detrimento de los datos que fundamentan la necesaria legalización.

Por nuestra parte, entendemos que si hoy la legalización del aborto está en disputa, esto se debe a fenómenos socioculturales que operan como condición de producción del acontecimiento y que intentaremos describir brevemente.

La historia del movimiento feminista en nuestro país es vasta por lo que pivotearemos sobre dos instancias que, creemos, sirvieron como puntapié del actual debate en torno al derecho a decidir. Por un lado, nos interesa recortar el papel de la Campaña por el Derecho al Aborto Legal, Seguro y Gratuito (“La Campaña”). Por el otro, y como ya hemos mencionando, el rol del nuevo movimiento de mujeres que irrumpió a partir del NiUnaMenos como hecho de masas que excedió los círculos activistas y militantes. En este sentido, y a modo de hipótesis precaria, argüimos que mientras la Campaña dio contenido al reclamo, la participación popular surgida a partir de la manifestación contra los femicidios el 3 de junio de 2015 formateó y dio masividad a este proceso que, en 2018, terminó con la discusión en el Congreso de la Nación del proyecto de ley de IVE.

\section{¿Qué entendemos por aborto?}

Aborto es la interrupción de un embarazo, mientras el embrión no pueda vivir por fuera del útero. Es decir, hasta alrededor de las 22 semanas de gestación. Si el proceso está más avanzado, se trata de un parto inducido, el que nace necesita cuidados especiales, pero puede sobrevivir.

En la actualidad, el aborto es ilegal, un hecho delictivo que figura en el Código Penal. Como indica Laura Belli: 
En Argentina, el aborto está penado por ley en casi todas las circunstancias, con sólo un par de excepciones. Su regulación se establece en el Código Penal vigente desde 1921. El Código anterior (1887) estipulaba sanciones a la práctica de interrupción del embarazo en absolutamente todos los casos, castigando el acto con la pena de prisión. Entre un documento y el otro se presentaron varios proyectos de ley que, en todos los casos, condenaron el aborto, sin prever ningún tipo de excepción (2018).

Las circunstancias excepcionales en que el aborto se convierte en una práctica legal son el riesgo para la vida o la salud de la madre y la violación. En estos casos, de llevarse a cabo, no hay sanciones ni para el médico ni para la paciente. Pero, como señalamos con anterioridad, este fenómeno de salud pública se entrama con un sinfín de patrones culturales, religiosos y morales que encuentran tierra fértil en amplios sectores de la corporación médica y el sistema judicial. Entre estos estratos no se consigna del derecho a decidir de la persona gestante sino el derecho a la vida del no nacido. Toda vida, plantean, sería intocable desde el momento de la concepción y, por eso, habría que "cuidarlas" a ambas. De esta forma, aun cuando esté contenido en el marco de la legalidad, muchas mujeres violadas no pueden interrumpir su embarazo:

Desde hace 95 años las mujeres tienen derecho a interrumpir legalmente su embarazo bajo ciertas causales. Sin embargo, casi nunca lo pueden ejercer. Aun cuando se encuadra en las situaciones previstas por la ley, son denunciadas policial y judicialmente, poniéndole frenos burocráticos para imposibilitar la decisión. A esto se suma la violencia psicológica y la condena social. Todavía prevalece la criminalización, como en el caso de 'Belén', la joven tucumana condenada a ocho años de prisión por un aborto espontáneo (Belli, 2018).

En el marco de los proyectos presentados en el parlamento argentino, se refiere la despenalización y la legalización del aborto. El primer concepto plantea la ausencia de sanciones penales para el médico que practica un aborto y para la mujer que lo pide. Por otra parte, la legalización obliga al Estado a responder a la demanda hecha por una embarazada en los centros de salud pública y en las obras sociales. 


\section{Aborto legal es justicia social}

Cabe destacar que en el país existe una amplia red clandestina de realización de abortos, con una escala tarifaria según las seguridades y comodidades que se ofrezcan para el proceso. Por eso, es una cuestión de salud pública vinculada con la desigualdad: las mujeres de sectores populares que no pueden costear ni la más baja de las tarifas, recurren al aborto en condiciones precarias, con métodos caseros y/o con personas sin calificación médica, arriesgando su salud y sus vidas. De esta forma, que el aborto se legalice es un fenómeno político que "repara la desigualdad de poder en la apropiación de las decisiones sobre los cuerpos gestantes" (Maffía, 2018).Como señala Amalia Arias Gozurreta:

Aquí la desigualdad social y económica se hace evidente. Las mujeres de altos ingresos pueden pagar un aborto sin riesgos en una clínica de las que aparecen en las cartillas de las prepagas top, al mismo tiempo que otra mujer de clase baja se somete a un procedimiento digno de película de terror, en consultorios con condiciones de higiene deplorables o en su misma casa (2018).

En este sentido, un sondeo de la consultora Graciela Römer y Asociados en 2001 (7) indicaba que 20 de cada 100 mujeres pobres que abortaban lo hacían con un médico; una proporción que alcanzaba a 60 de cada 100 en los sectores medio, y al 83 por ciento en las clases de mayores ingresos. En este sentido, y dando lugar a la perspectiva antropológica de Shore (2010) para reflexionar sobre una política pública, es importante considerar las diversas dimensiones de la desigualdad para explorar, así, "cómo se articulan las disparidades económicas con la concentración del poder y con los procesos de construcción cultural de la diferencias" (Reygadas, 2004: 347). Como venimos señalando, la ilegalidad del aborto es otro registro más de la desigualdad que atraviesa nuestra sociedad. Así, mientras los estratos altos interrumpen sus embarazos no deseados en condiciones de salubridad, las mujeres de sectores populares son lanzadas a precariedades de todo tipo que reproducen sus ciclos de exclusión. La percha, la aguja de bordar y el perejil como símbolos del clasismo furtivo.

Por otra parte, como ya señalamos, si las mujeres pobres concurren a los hospitales públicos, se encuentran con que ni siquiera en los casos en que el aborto es legal, tienen garantizada la atención médica. Incluso pueden ser denunciadas y maltratadas por las y los profesionales que, si bien objetan conciencia al momento de practicar un aborto legal, muchas y muchos sostienen una industria clandestina que, en 2010, movió mil millones de pesos: 
Si bien fueron muchísimos los profesionales que en su debido momento presentaron su objeción de conciencia para practicar abortos dentro del protocolo de Aborto no punible e incluso se organizaron en ONGs y campañas activas para lograr el mayor número de adhesiones posibles a su negativa, lo llamativo es que la industria del aborto clandestino involucró \$1000 millones en 2010, que fueron directo a médicos, laboratorios y farmacias. Mientras tanto, en 2015 se invirtieron $\$ 72.730 .000$ (el 7\%) en métodos anticonceptivos dentro del Programa de Salud Sexual y Procreación Responsable del Ministerio de Salud de la Nación, programa que al día de hoy no tiene garantía de continuidad, porque si bien el Gobierno asegura que los medicamentos y preservativos se van a seguir distribuyendo a pesar de los recortes, no hace lo mismo sobre el acompañamiento de los profesionales en el correcto uso de las distintas opciones anticonceptivas (Arias Gozurreta, 2018).

Ahora bien, hay mujeres que quedan embarazadas sin proponérselo por fallas en las medidas anticonceptivas o por desconocimiento de las mismas. Por esto, el reclamo del movimiento de mujeres en torno a la IVE se articula con la demanda de educación sexual integral en la adolescencia. En este sentido, y a pesar de su relevancia, el Programa de Educación Sexual Integral (ESI) del Ministerio de Educación de la Nación (7) ha sido implementado de diversas formas en las provincias del país debido a resistencias del orden moral y/o religioso vehiculizadas por grupos e instituciones locales. Así, hay escuelas que al día de hoy "siguen sin tocar el tema o enseñan contenidos confusos y mezclados con sus creencias" (Arias Gozurreta, 2018).

Por esto, la educación sexual integral así como la legalización del aborto implican "reconocer la dignidad, la plena autoridad, la capacidad y el derecho de las mujeres" para dirigir sus vidas y que "el derecho a decidir sobre el propio cuerpo es un derecho personalísimo ya que éste es el primer territorio de ciudadanía de todo ser humano" (Maffía, 2018).

\section{El contenido de la disputa: Campaña Nacional por el Derecho al Aborto Legal, Seguro y Gratuito}

La Campaña viene cimentando el proceso en torno a la IVE, que irrumpió, de manera masiva, en 2018, desde hace trece años; congregando, a su vez, experiencias que la antecedían. Es por esto que entendemos que su activismo en favor de la organización y coordinación entre sectores nacionales e internacionales, el cabildeo parlamentario, y la producción de línea argumentativa a partir de materiales de difusión e intervenciones de sus referentes en el debate 
público; dio contenido a la disputa por el sentido del aborto. Como reseña Mabel Belucci, la Campaña

fue pensada a partir del deseo de más de 20 mil mujeres reunidas en el XIX Encuentro Nacional de Mujeres, llevado a cabo en Mendoza en 2004. Al año siguiente, se lanzó al ruedo, en el marco de la conmemoración del 28 de mayo -Día Internacional de Acción por la Salud de las Mujeres- con el lema 'Educación sexual para decidir, Anticonceptivos para no abortar y Aborto legal para no morir'. En ese momento, intervenían alrededor de 70 organizaciones de mujeres de todo el país" (2011).

Según la página oficial de la campaña (8), los objetivos estratégicos del armado, conteniendo la pluralidad de formas de expresión para lograrlos, son: instalar en la sociedad y en el Estado el debate en torno a la necesidad de despenalizar y legalizar el aborto en el país, contribuir a que más mujeres y organizaciones se sumen en este proceso y reclamo y lograr el debate y la aprobación de una norma legal que despenalice y legalice el aborto en Argentina. A su vez, plantea un lema integral que concibe a los derechos sexuales y los derechos reproductivos como derechos básicos de todas las personas: "Educación sexual para decidir, anticonceptivos para no abortar, aborto legal para no morir".

Si bien el aborto es una demanda histórica del movimiento feminista, creemos, como ya indicamos, que con la creación de la Campaña Nacional por el Derecho al Aborto Legal, Seguro y Gratuito en 2005 se estructura el reclamo a partir de esta instancia de articulación de organizaciones y referentes. Es decir, planteamos que la tarea llevada adelante por este espacio -como el más significativo entre otros-, da contenido y argumento colectivo a los posicionamientos favorables en relación a la legalización de la IVE que, en 2018, irrumpieron en la agenda social, cultural, mediática y parlamentaria de la Argentina. En este contexto, parte de los lineamientos y dimensiones trabajadas por la Campaña vienen a discutir con el sentido común que, históricamente, operó desde abordajes del orden moral y religioso, mitologizando, en su proscripción, un fenómeno de salud pública. Hablamos de "mito" porque entendemos, con Shore (2010), que la discusión en relación con la IVE, a un lado y al otro, "proveen una zona de alianza, una manera de unir a la gente en pro de una meta o finalidad común y un mecanismo para definir y mantener las fronteras simbólicas que nos separan a 'nosotros' de 'ellos'” (p. 32).

El colectivo cuenta actualmente con la adhesión de 305 grupos, organizaciones y referentes vinculados a organismos de derechos humanos, de ámbitos académicos y científicos, trabajadoras/es de salud, sindicatos y diversos movimientos sociales y culturales, entre ellos 
redes campesinas y de educación, organizaciones de desocupadas/os, de fábricas recuperadas, grupos estudiantiles, comunicadoras y comunicadores sociales, etcétera. Esta articulación multisectorial logró posicionar a la Campaña en el debate público como interlocutora en reclamos al poder legislativo, judicial y ejecutivo. En este sentido, como indican Martha Rosenberg y Elsa Schvartzman, cada vez más convocada y reconocida, la campaña:

Fue convirtiéndose en un actor social insoslayable en el momento de tomar posición, recuperar la historia, promover la conquista de nuevos derechos y exigir el cumplimiento de los ya vigentes, aunque muchas veces negados. En la declaración inaugural dijimos: 'La clandestinidad del aborto no impide su realización, aumenta los riesgos y atenta contra la dignidad de las mujeres y de toda la sociedad. No queremos ni una sola muerte más por abortos clandestinos' (2014).

En 2018, la campaña presentó su proyecto de interrupción voluntaria del embarazo por séptima vez. Pero, a diferencia de otras oportunidades, la propuesta -unificada con otros proyectospudo ser aprobada en Diputados.

En este sentido, entendemos que este avance no es resultado de la vocación progresista de un gobierno de derecha (9) sino que es fruto de la movilización y masificación que viene produciéndose en el movimiento feminista, a escala local, y de la irrupción política de la agenda de las mujeres, en un contexto globalizado, a nivel internacional. De las movilizaciones del \#NiUnaMenos en la Argentina al \#MeToo o el Time's Up en EE. UU. Cambio de época encarnado que discute con uno de los cimientos de las sociedades modernas, el patriarcado; y desnaturaliza prácticas que reproducen tipologías y formas de dominación y opresión de género. Desde los femicidios al "piropo" callejero, desde el aborto a la desigualdad entre hombres y mujeres. En este sentido, cabe recuperar, siguiendo a Díaz, Impemba, Irizarry y Steiner (2013), que el trato desigual y jerarquizado respecto al género en lo social "produce las condiciones para que opere violencia contra la mujer" (p. 2) de diferentes formas. Así, la ilegalidad del aborto es una línea más de este tejido de violencia(s).

Además, retomando a Reygadas (2004), en la etapa profunda de la globalización, se trata de develar las diferentes formas de explotación que se anudan al entramado patriarcal a escala mundial sin perder los particularismos y las diferencias. Como señala la politóloga Tania Rodríguez:

Dentro de un escenario de diversidad y complejidad, es posible encontrar elementos y trayectorias comunes en los distintos movimientos feministas del continente. Lejos de la 
mirada homogeneizante, se trata de llevar a la práctica una perspectiva decolonial y popular, que reconozca las numerosas formas de opresión que históricamente se sumaron a la sujeción patriarcal (2018).

En este contexto, se inscribe el devenir del proyecto por el aborto y las estrategias posteriores tomadas por la campaña, y el movimiento de mujeres en su conjunto, para discutir con el sentido común misógino, moral, clasista y religioso naturalizado. Sin olvidar que, como señala Antonio Gramsci (1971), el sentido común es "la filosofía de los 'no filósofos', o sea la concepción del mundo absorbida acríticamente de los varios ambientes culturales en medio de los cuales se desarrolla la individualidad moral del hombre medio" (p. 125). Entonces, la disputa demanda diferentes astucias para masificar el reclamo y desmitificar el fenómeno.

Es por esto que, en el marco de la disputa por el sentido, y alrededor del debate en Diputados, se construyó una red argumentativa/cultural para solidificar las posiciones, amplificar la demanda y dar continuidad a la llamada "revolución de las hijas" (10), las "anti princesas" (11) que tomaron el espacio público. El clima de época es tal que el 22 de julio de 2018, el periódico Clarín destinó parte de su portada y la tapa de su revista dominical ("Viva") a las "Pibas F: feministas antes de cumplir 18" (Figura 1).

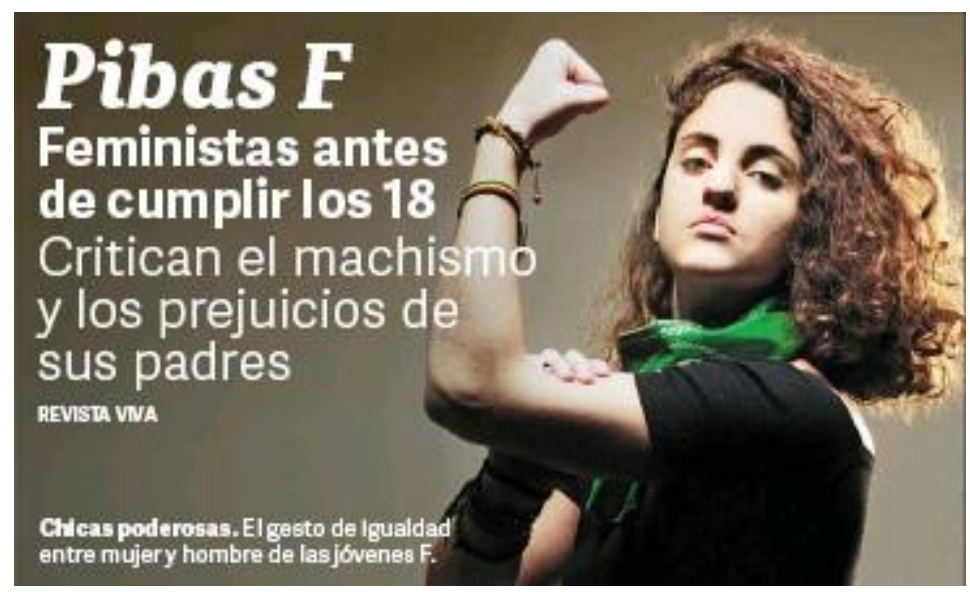

Figura 1: Fragmento de tapa del diario Clarín. Fuente: Clarín, 22 de julio de 2018.

De esta forma, en la primera mitad de 2018, las cuestiones relativas al aborto, en particular, y los derechos de las mujeres, en general, ocuparon las páginas de revistas y matutinos, pulularon en las redes sociales y en la televisión abierta (12). A su vez, la Campaña organizó diferentes actividades que buscaron interpelar a la sociedad en su conjunto. Propuestas como los festivales musicales organizados frente al Congreso de la Nación todos los martes de mayo 
de 2018 durante las reuniones informativas y el proceso de discusión en la cámara de Diputados llamados los "Martes verde" (Figura 2), las publicaciones masivas en la plataforma Twitter de un hashtag puntual para convertirlo en trending topic conocidas como "Tuitazos" (Figura 3); o las concentraciones llamadas "Pañuelazos" en las que se muestran pañuelos verde -símbolo de la campaña y la lucha por el aborto- como forma de visibilizar al movimiento a favor del derecho a decidir; son parte de las estrategias integrales para desarmar lo naturalizado y lograr legislación. Así, en esta disputa, se trata de "posicionar a la cultura como un agente de transformación social y revelar las dimensiones culturales de fenómenos aparentemente no culturales" (Vich, 2014: 85). Ir desmontando los imaginarios hegemónicos en torno a la mujer y el embarazo. Como respuesta, los sectores contrarios al IVE construyeron un feto gigante, regimentaron utilizar pañuelos celestes y enviaron figuras de embriones en cajas delicadas a los legisladores.
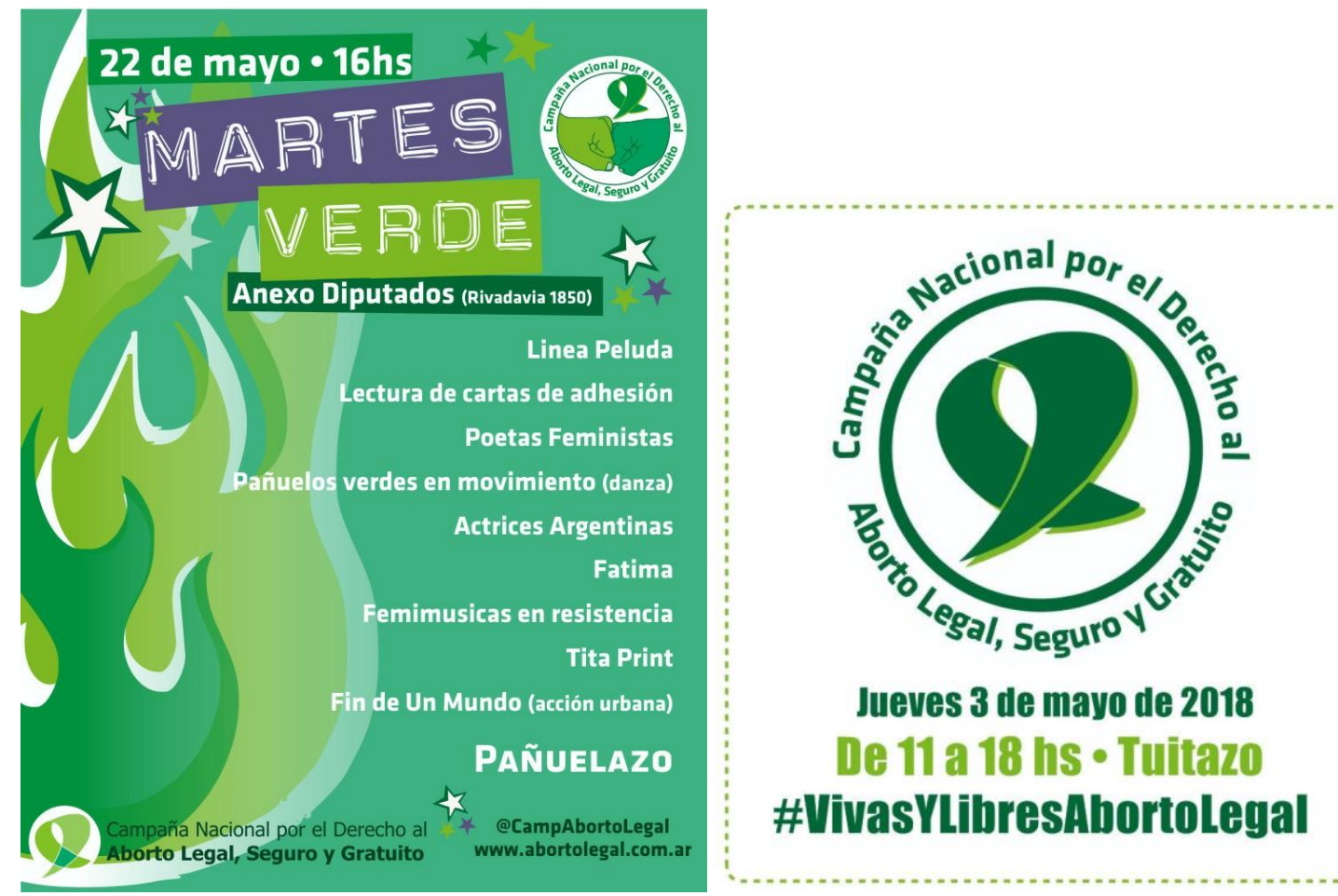

Figura 2: Flyer "Martes verde"/Figura 3: Flyer difusión "tuitazo". Fuente: Campaña Nacional por el Derecho al Aborto Legal, Seguro y Gratuito 
La forma de la disputa: el NiUnaMenos, la masividad y la irrupción en el espacio público

Para deconstruir estos imaginarios hegemónicos, retomamos tres simbologías que funcionan en la publicidad como estereotipos de la mujer. En el contexto de la sociedad occidental y capitalista contemporánea estas marcas se transforman en racionalidad para pensar a lo femenino (Díaz et al., 2013). Así, la mujer inherentemente madre, la pasividad erótica femenina y la asociación con el universo de lo subjetivo; funcionan como patrón y delimitan conductas apropiadas e inapropiadas, potestades y exclusiones. En este sentido, y en relación con el último estereotipo, el ámbito de despliegue público y la política, no sería "cosa de mujeres".

De esta forma, en la exposición de este anclaje de sentido se torna aún más transgresora la irrupción callejera de las mujeres el 3 de junio de 2015 en el llamado \#NiUnaMenos y el comienzo de la masificación del movimiento. Es decir, un momento en que la agenda feminista trascendió los espacios activistas para tornarse fenómeno de masas. Entendemos que este proceso es el que nutre la movilización social en relación con el proyecto de IVE y se embandera con los lineamientos acordados en el marco de la Campaña Nacional por el Derecho al Aborto Legal, Seguro y Gratuito.

Ya a fines de marzo de 2015, periodistas, investigadoras y militantes, se reunieron en los jardines del Museo de la Lengua para manifestarse contra los femicidios. Luego del asesinato de Chiara Páez, unos meses después, las redes sociales y acciones de este espacio lograron instalar una breve consigna en diversos ámbitos que logró verse materializada en multitudinarias marchas en toda la Argentina el 3 de junio del mismo año: Ni una menos. El antropólogo Alejandro Grimson y la comunicóloga Lucila Schonfeld plantearán, al día siguiente, que:

Ya nada será igual. De ahora en más, el 3 de junio de 2015 es un día histórico en la lucha por los derechos de las mujeres, contra la violencia de género y los femicidios. Una lastimadura dolorosa para la cultura patriarcal, de la que todos y todas formamos parte (2015).

Como apuntó el colectivo impulsor a través de un comunicado posterior (13), el movimiento espontáneo nombró un estado de ánimo colectivo, un rechazo a la violencia machista que estaba latente en la sociedad. Ese llamado encontró en las redes sociales un medio para multiplicar las voces y viralizó el mensaje. De ahí el hashtag (\#) delante de la consigna NiUnaMenos. Así, el acontecimiento se dio en más de 120 plazas y localidades del país en 
simultáneo. A su vez, la convocatoria fue plural y estuvo marcada por la transversalidad política, social y cultural.

Hay un antes y un después del 3 de junio. Fue el 17 de octubre de los derechos de las mujeres. Modificó radicalmente la visibilidad de esa lucha y su legitimidad pública. Un día histórico que promete quedar en la memoria e inspirar nuevos cambios (Grimson y Schonfeld, 2015).

A partir de ese suceso, las manifestaciones y acontecimientos relativos a los derechos de las mujeres en la Argentina cobraron dimensiones de masas. De esta manera, días como el de la mujer (8 de marzo) o el de la no violencia contra la mujer (25 de noviembre) pasaron a ser jornadas de lucha. De aceptar obsequios, flores y bombones, a tomar la calle y encarar un paro internacional de mujeres (14), el fenómeno que comenzó en 2015 logró visibilizar una agenda oculta por la naturalización y preeminencia de prácticas e imaginarios patriarcales. Como consecuencia, mujeres de todas las edades y clases sociales se sumaron a espacios de debate colectivo, formativos y asamblearios. También, problematizaron sus cotidianeidades y comenzaron a discutir sus ámbitos familiares, relacionales y laborales, sus escuelas y sindicatos. Así, esta dimensión interpeló de manera intensa los fundamentos estructurales de la sociedad y sentó precedente para las formas en que hoy se construye la movilización en torno al aborto.

A su vez, el NiUnaMenos tuvo impacto internacional. Desde 2015, el fenómeno comenzó a sucederse en diferentes ciudades de Latinoamérica y el mundo. Como reseña la periodista mexicana Cecilia González:

La movilización tuvo impacto internacional. Tanto, que hasta Michelle Obama habló del 'Ni una menos' cuando vino junto con su esposo en marzo a Buenos Aires. (...) Y la movilización en México, también inédita, al amparo del lema 'Vivas nos queremos', precedida por un 'tuitazo' en el que miles de mujeres contaron su primer abuso. Desde violaciones cuando eran niñas, hasta interminables manoseos en la vía pública (2016).

Las movilizaciones se expresaron con las particularidades de cada localidad pero encontrando lo común en medio de la diversidad: la opresión de la mujer. Porque, como destaca Aida Hernández Castillo (2003), construir un feminismo latinoamericano de la diversidad debe reconocer "la pluralidad de contextos en los que las mujeres construimos nuestras identidades de género, vivimos las relaciones de desigualdad y desarrollamos nuestras estrategias de 
lucha" (p. 21). Es decir, no hay recetas ni fórmulas únicas sino articulaciones creativas de un movimiento vivo y dinámico.

\section{Exposiciones y debate en Diputados: pasaron cosas}

Como hemos detallado, el comienzo del proceso que terminó en el debate en la Cámara de Diputados fue la presentación, por séptima vez, del proyecto de la Campaña Nacional por el Derecho al Aborto Legal, Seguro y Gratuito, en 2018, apoyado por más de 500 organizaciones y el movimiento feminista en general. También, a diferencia de otros años, y por razones que hemos marcado, el tema de la IVE y el universo de sentido que repone, trascendió los círculos militantes e irrumpió en el cotidiano de la ciudadanía. Así, en las familias, las escuelas, universidades y ámbitos laborales, en el taxi y el subte, el aborto fue tema de discusión entre las y los argentinos y argentinas. Las exposiciones de especialistas así como las reflexiones de los diputados fueron televisadas, difundidas por los noticieros y los diarios, compartidas en las redes sociales. Movilizaciones a favor y en contra fueron transmitidas. Los pañuelos verdes se viralizaron en las mochilas de los adolescentes y el emprendedorismo callejero, como eficaz termómetro de lo social, comenzó a comercializarlo en las principales avenidas de Buenos Aires. "Hay pañuelos, pañuelos, pañuelos", que no son para el resfrío del invierno argentino.

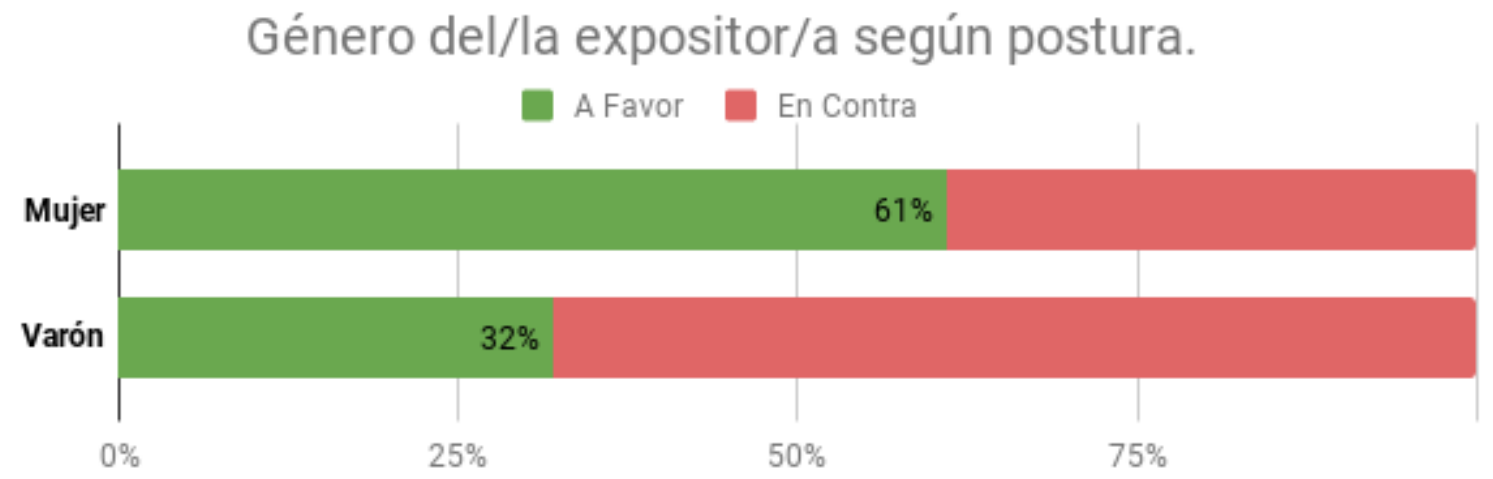

Figura 3: Fuente: http://economiafeminita.com/

Por los plenarios de las comisiones (15) de Diputados -previo al debate en la Cámara-, que 
iniciaron el 10 de abril de 2018 y finalizaron el 31 de mayo del mismo año, pasaron, en promedio, cincuenta expositores diarios, sugeridos por los propios legisladores, repartidos en mitades a favor y en contra de la legalización del aborto. En este sentido, nos interesa retomar los gráficos publicados por el portal Economía Feminista en el que se releva el género de los expositores según su postura en relación con el proyecto (Figura 3) y el abanico de instituciones identificadas, también, según posicionamiento.

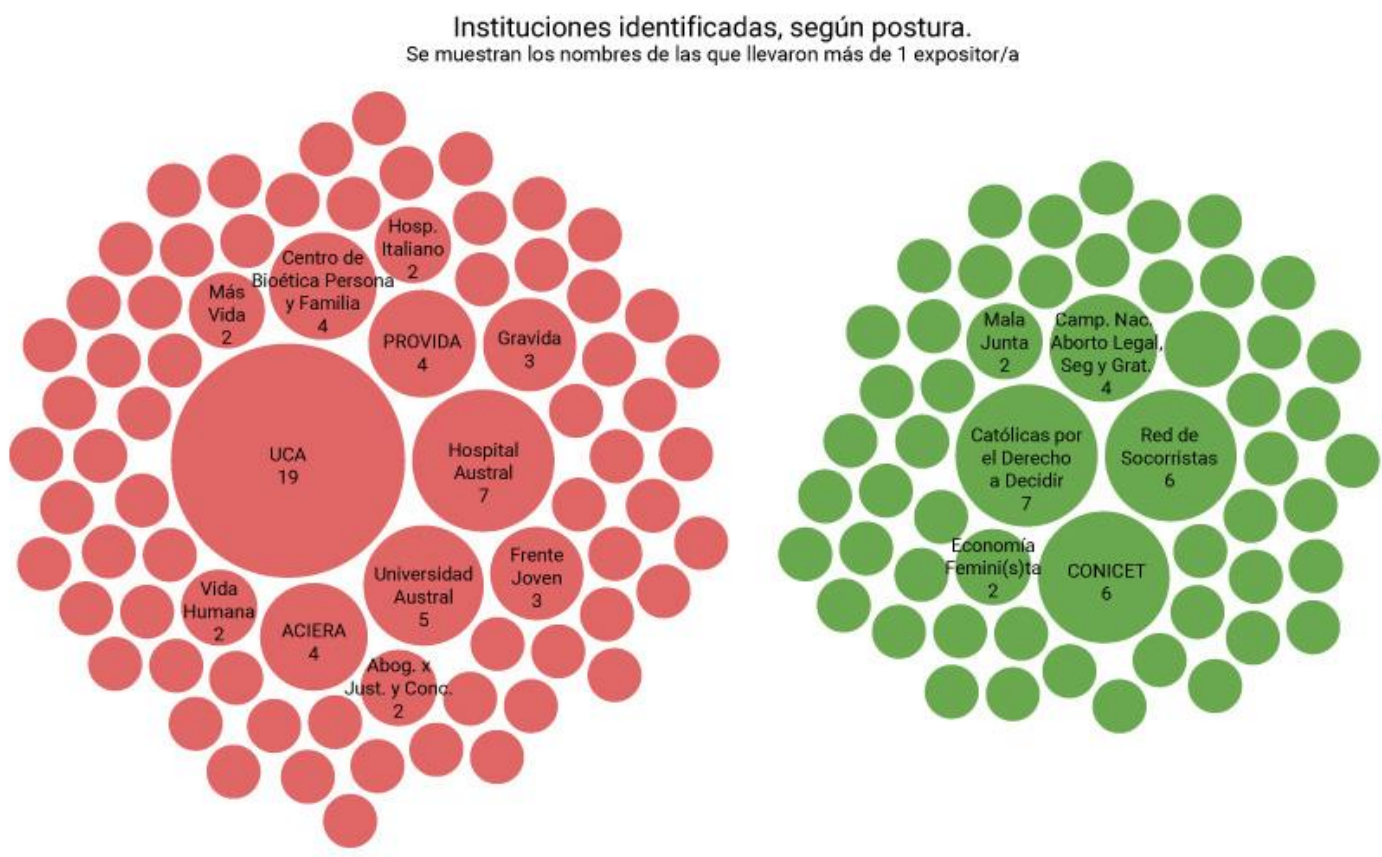

Figura 4: Fuente: http://economiafeminita.com/

Entendemos que reponer estos esquemas da fundamento estadístico a lo que venimos exponiendo en torno a las estructuras patriarcales de nuestra sociedad y la resistencia de los espacios conservadores vinculados con la religión.

De esta forma, mientras que un $61 \%$ de las mujeres que expusieron lo hicieron a favor del proyecto, un $68 \%$ de los hombres expositores lo hicieron en contra. A su vez, se torna interesante pensar cómo en estos posicionamientos siguen operando argumentos misóginos contra un fenómeno que involucra a las mujeres, sus cuerpos y sus derechos. Por otra parte, como marcamos a lo largo del trabajo, a los postulados científicos y fundados en menguar las desigualdades; se le oponen, tendencialmente, definiciones asentadas en la moral y el credo. 
Así, es destacable consignar la pertenencia a una constelación de organizaciones feministas (Mala Junta, Campaña Nacional por el Aborto Legal, Seguro y Gratuito, Católicas por el Derecho a Decidir, Red de Socorristas, Economía Feminista) y el Consejo Nacional de Investigaciones Científicas y Técnicas (CONICET) de quienes están a favor del proyecto de IVE en contraste con un conglomerado de instituciones vinculadas con la Iglesia Católica que se pronunciaron contra la propuesta (Universidad Católica Argentina, Universidad y Hospital Austral, Frente Joven, PROVIDA, etcétera; Figura 5).
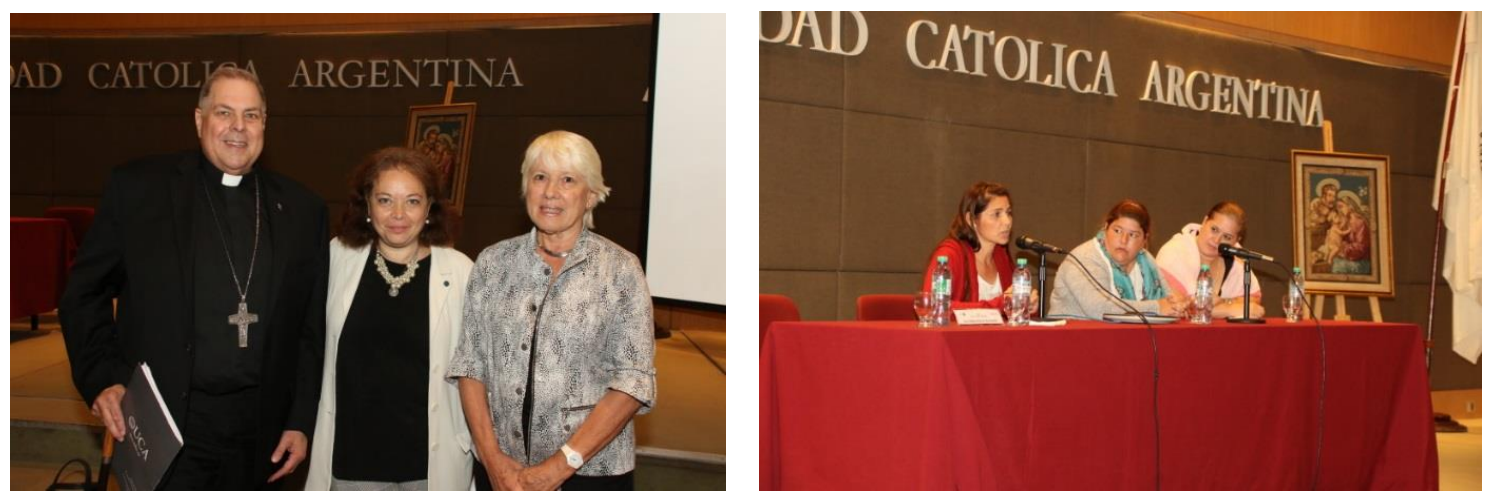

Figura 5. Jornada "Aborto: una reflexión indispensable" organizada por el Instituto para el Matrimonio y la Familia de la Universidad Católica Argentina (UCA) - Abril 2018. Fuente: UCA

En las exposiciones plenarias, los argumentos tendieron a repetirse, tanto de un lado como del otro. En virtud de ello, retomamos algunos de los más mencionados a partir de los relevamientos de Olivia Sohr y Lucía Martínez (2018) quienes se ocuparon de sistematizar los dichos y contrastarlos con información estadística o de fuentes veraces.

De acuerdo con esto, postulados favorables y verificados en relación con el aborto como que su legalización reduce la mortalidad materna (esto está fundado en que un proceso de interrupción del embarazo en condiciones de seguridad no conlleva mayores riesgos para la mujer gestante) o que en la mayoría de los países desarrollados la IVE es legal fueron discutidos -tanto en los plenarios como en la Cámara- con argumentos asentados en las creencias, refutadas en términos legales y estadísticos, que la legalización es inconstitucional o que con ella los abortos aumentan. Según Sohr y Martínez:

La evidencia existente sobre los países en los que se legalizó la interrupción voluntaria del embarazo no muestra que haya un aumento en la cantidad de abortos a largo plazo. Es difícil tener datos exactos de la cantidad de abortos que se producen antes de la 
legalización, dado que no existen estadísticas oficiales de prácticas ilegales, pero aunque las estadísticas muestran en ciertos casos un aumento inicial, a largo plazo la práctica se estabiliza o disminuye (2018).

A su vez, un planteo articulador del entramado "antiaborto", como indicamos al comienzo del artículo, es la supuesta preocupación por cuidar "las dos vidas". Eso implicaría la preocupación tanto por la mujer gestante como por el "niño por nacer". Pero, como manifiesta Maffía:

Se puede defender el derecho a la vida de las personas nacidas y en etapas gestacionales sin penalizar el aborto. La vida se defiende positivamente y no mediante prohibiciones, nosotras defendemos la vida. (...) La legalización disminuye las muertes maternas y también disminuye el número de abortos. La conclusión es lógica: si quieren salvar las dos vidas, como dicen, aprueben la ley de interrupción voluntaria del embarazo (2018).

Entonces, recapitulando desde el inicio, más allá de los posicionamientos y argumentos a favor y en contra; todxs abortan. Las clases bajas, medias y altas; los sectores ateos y los confesionales. Lo que se discute, de manera latente, no es abortó sí o no, sino en qué condiciones se darán las IVE, si en circunstancias seguras y legales o precarias y clandestinas; diferencia que recupera las dimensiones más violentas de la estratificación clasista: mientras las ricas abortan, las pobres mueren en nombre de "las dos vidas" o "bebito ingeniero".

\section{Conclusiones interinas}

Lo provisorio intenta atentar contra un horizonte conclusivo estable. Entendemos que el que intentamos reponer es un proceso vivo, que está sucediendo y atraviesa a la sociedad toda. Por eso, asumimos, también, que es un movimiento contingente. Es decir, podemos dar cuenta y relevarlo históricamente, trazar hipótesis y articular fenómenos pero, de ninguna manera, profetizar su devenir.

Ahora bien, sí hemos trazado algunas líneas que sirven de hilo conductor para intentar aprehender algunas de las tramas que componen este tejido de resistencia. Así, caracterizamos que hubo un relanzamiento del movimiento de mujeres en el país a partir de las movilizaciones del Ni Una Menos y el proceso de masificación de los ámbitos feministas y de la agenda de género. Como contrapartida, manifestamos que estos sucesos, en su crecimiento, desbordaron a las estructuras organizacionales y militantes que los antecedieron. De esta 
forma, no solo los espacios activistas fueron desbordados por esta "marea verde" sino que el debate en torno a los roles, los cuerpos, los sentidos y las desigualdades, trascendieron los ámbitos enclaustrados de la reflexión ideológica. Como dijimos, en las casa y los trabajos, en las escuelas y sindicatos, se comenzó a discutir lo naturalizado, lo de sentido común. A su vez, este proceso brindó los repertorios de acción para que la disputa por la IVE -de este lado de la barricada- se diera como se dio: festivales, tuitazos, pañuelazos, movilizaciones dieron forma a la batalla -en términos gramscianos- sociocultural y política por el derecho a decidir. También, indicamos que las principales líneas directrices y ejes de acción en relación con el proceso, y en vínculo con el recorrido institucional del proyecto de ley, fueron signados y dispuestos a partir del espacio supra organizacional de la Campaña brindando un entramado de contenido, argumentos y simbología.

Entonces, forma y contenido se comulgaron para lograr que, en 2018, la IVE se instale en la agenda mediática, discuta con el sentido común y aporte a la deconstrucción de imaginarios culturales hegemónicos. De esta manera, por primera vez en la historia de la Argentina, es del orden de la posibilidad que el aborto sea legal, seguro y gratuito. ¿Será esta la pleamar del movimiento feminista local?

\section{Notas}

(1) El término "persona gestante" se comenzó a utilizar en la última revisión del Ministerio de Salud de la Nación para el protocolo para la atención integrar de las personas con derecho a la interrupción legal del embarazo, en 2015, y fue incluido en el artículo 2 del proyecto de Ley de Interrupción Voluntaria del Embarazo presentado en el Parlamento argentino en 2018. Como señala Natalia Gherardi, directora ejecutiva del Equipo Latinoamericano de Justicia y Género (ELA): "se hizo pensando en personas que no son mujeres, pero tienen capacidad de gestar como ocurre, por ejemplo, con los varones trans. También contempla a los que no se encasillan en un determinado género, que se identifican como de género fluido". Recuperado de https://www.clarin.com/sociedad/aborto-proyecto-refiere-mujeres-personasgestantes_0_B1cNbapxX.html

(2) En artículo en el matutino La Nación, el periodista Sergio Suppo (2018) afirma que "son también los dirigentes los que fallan cuando vuelven a poner a la sociedad en otra grieta política. Es ese fanatismo lo que bastardea la discusión sobre el aborto, en especial en la televisión y mucho más en las redes sociales. La discusión se plantea con una lógica de extremos, condicionada por los parámetros desesperados del rating y del clic. No hay margen para matices, miradas en diagonal ni, mucho menos, para tolerar un intento de comprensión de los argumentos ajenos".

(3) "En su acepción media, la idea de repertorio presenta un modelo en el que la experiencia acumulada de los actores se entrecruza con las estrategias de las autoridades, dando como resultado un conjunto de medios de acción limitados, más práctico, más atractivo y más frecuente que muchos otros medios que podrían, en principio, servir los mismos intereses" (Tilly, 1984: 99). 
(4) Fruto de estas pujas es que al proyecto inicial, que tomaba como piedra basal la propuesta elaborada por la Campaña Nacional por el Derecho al Aborto Legal, Seguro y Gratuito, se le incorporaron modificaciones con el fin de sumar adhesiones. En este sentido, la iniciativa avala la realización de la IVE hasta la semana 14, inclusive, del proceso gestacional, estableciéndose con claridad las excepciones. Fuera de este lapso el aborto se garantiza en caso de que el embarazo haya sido producto de una violación o de que estuviera en riesgo la vida o salud de la persona gestante. Los y las menores de 16 años que accedan a la IVE deberán hacerlo con su consentimiento informado, en coherencia con la Convención sobre los Derechos del Niño. Además, se consignan las responsabilidades que deben cumplir las instituciones de salud adonde acuda la persona para ser asistida: deben garantizar el proceso sin que medie autorización judicial previa, la objeción de conciencia para los profesionales tiene que ser informada de manera previa, individual y por escrito, a las autoridades del establecimiento; y debe incorporar instancias de consejerías pre y pos IVE, un ítem que se añadió para atraer a los legisladores de "indecisos". Recuperado de http://www.parlamentario.com/noticia-110537.html

(5) Datos cantidad de abortos: promedio entre 360 mil y 550 mil es el resultado de un trabajo realizado en 2005 por dos demógrafas (especialistas que estudian la evolución de la población), Edith Pantelides y Silvia Mario, a pedido del Ministerio de Salud de la Nación. Este dato se desprende de una estimación estadística realizada sobre datos disponibles de hospitales públicos (número de casos hospitalizados por complicaciones de aborto) y datos relacionados con salud sexual y reproductiva (provenientes de estadísticas vitales, censos y encuestas).

(6) "Para Ivana Bianchi, del bloque Unidad Justicialista, hay evidencia suficiente para afirmar que en otros países se paga hasta 100 dólares por feto para extraerle los órganos. 'Existen videos en donde una doctora de esa empresa dice 'somos muy buenos para conseguir el pulmón, el corazón, el cerebro o el hígado, porque no aplastamos esas partes, presionamos por arriba y por abajo para sacar esas partes íntegras", explicó la diputada sobre su investigación en YouTube. 'Ocurre en el Reino Unido. También hay tráfico de cerebros de fetos en Francia. Por eso me pregunto: ¿cuál va a ser el destino de estos fetos, van a ir a bolsas, van a ir a investigación, van a ser comercializados?', agregó por último". Recuperado de https://www.pagina12.com.ar/121581-los-7-peores-argumentos-de-los-antiderechos

(7) Información relevada en el artículo "Yo Aborté" de la revista Rolling Stone, 1 de febrero de 2003. Recuperado de https://www.lanacion.com.ar/582958-yo-aborte

(7) Programa sustentado en la sanción de la Ley 26150 de Educación Sexual Integral en 2006.

(8) www.abortolegal.com.ar

(9) Alianza de gobierno Cambiemos integrada, a nivel nacional, por: Unión Cívica Radical, Partido Demócrata Progresista, Partido Conservador Popular, Coalición Cívica-Afirmación para una República Igualitaria (ARI), Propuesta Republicana (PRO), Partido Fe, Partido del Diálogo.

(10) Término acuñado la periodista Luciana Peker que refiere a la masividad y el empuje que imprimieron las nuevas generaciones al movimiento de mujeres. Niñas y adolescentes, herederas, fogueadas en los años del \#NiUnaMenos que discuten desde su irreverencia con lo más estratificado del hecho patriarcal. Recuperado de https://www.pagina12.com.ar/110901-la-revolucion-de-las-hijas

(11) "Anti princesas" refiere a una colección de cuentos infantiles de Chirimbote y la editorial Sudestada que, desde una perspectiva de clase y género, destaca a mujeres ("antiprincesas") y hombres ("antihéroes") históricos discutiendo con los estereotipos de reconocimiento capitalistas y patriarcales. Cabe resaltar que la publicación inició en el mismo mes y año en que se produjo la primera manifestación del \#NiUnaMenos.

(12) Como hecho sugerente, cabe rememorar que el programa "Intrusos en el espectáculo" que se emite por el canal de televisión abierta América TV, abordó el tema del aborto en una sucesión de emisiones a partir de la invitación a debatir al estudio a diferentes referentes del feminismo argentino como las periodistas Luciana Peker y Julia Mengolini, o la actriz Malena Pichot.

Question, Vol. 1, N. 60, octubre-diciembre 2018. ISSN 1669-6581

Instituto de Investigaciones en Comunicación | Facultad de Periodismo y Comunicación Social | Universidad Nacional de La Plata | La Plata | Buenos Aires | Argentina

Página 19 de 21 
(13) Documento del Colectivo Ni Una Menos posterior a las movilizaciones.

(14) El primer paro internacional de mujeres se realizó el 8 de marzo de 2017.

(15) Comisiones de Legislación General, Legislación Penal, Familia, Mujer, Niñez y Adolescencia y de Acción Social y Salud Pública.

\section{Bibliografía}

Arias Gozurreta, A. (2018). Aborto (o de perchas de las que no cuelga ropa y perejil que no se usa en salsas). Economía Feminista. Recuperado de http://economiafeminita.com/aborto-o-de-perchas-de-las-que-no-cuelga-ropa-y-perejilque-no-se-usa-en-salsas/

Belli, L. (2018). Marco legal del aborto en Argentina: historia de un reclamo vigente. Economía Feminista. Recuperado de http://economiafeminita.com/marco-legal-del-aborto-enargentina-historia-de-un-reclamo-vigente/

Belluci, M. (2011). La Campaña Nacional por el Derecho al Aborto Legal, Seguro y Gratuito. Revista Herramienta. Recuperado de http://www.herramienta.com.ar/articulo.php?id=1475

Colectivo Ni Una Menos (2015). Un nuevo Nunca Más. Revista Anfibia. Recuperado de http://www.revistaanfibia.com/cronica/un-nuevo-nunca-mas/

Díaz, M. E.; Impemba, J.; Irizarry, R. y Steiner, A. (2013). La violencia contra la mujer en Argentina: entre logros y desafíos. En Pena, N.; Pereyra, B. y Soria, V. (editores). Desarrollo y derechos de las mujeres. Participación y liderazgo en organizaciones comunitarias (pp. 91-105). Buenos Aires: CICCUS.

Gramsci, A. (1971). El materialismo histórico y la filosofía de Benedetto Croce. Buenos Aires: Nueva Visión.

Grimson, A. y Schonfeld, L. (2015) Ni una menos: nada será igual. Revista Anfibia. Recuperado de http://www.revistaanfibia.com/cronica/nada-sera-igual/

González, C. (2016). Un movimiento sin dueñas. Revista Anfibia. Recuperado de http://www.revistaanfibia.com/cronica/movimiento-sin-duenas/

Hernández Castillo, R. (2003). Re-pensar el multiculturalismo desde el género. Las luchas por el reconocimiento cultural y los feminismos de la diversidad. En Revista de Estudios de Género. La ventana, 18, pp. 9-39, diciembre, Universidad de Guadalajara, México.

Maffía, D. (2018). Diana Maffía en el Congreso. Economía feminista. Recuperado de http://economiafeminita.com/diana-maffia-en-el-congreso/ 
Reygadas, L. (2007). La desigualdad después del (multi)culturalismo. En Giglia, A; Garma, C. y De Teresa, A. (compiladores). ¿Adónde va la Antropología? (pp. 341-364). México: Universidad Autónoma Metropolitana.

Rodríguez, T. (2018). Feminismos populares en América latina. La construcción de un nuevo sentido común. Revista Voces del Fénix, 69, julio. Recuperado de https://bit.ly/2Pr78Eh

Rosenberg, M. y Schvartzman, E. (2014). La Campaña Nacional por el Derecho al Aborto Legal, Seguro y Gratuito. La lucha por el derecho al aborto: una deuda de la democracia. Revista Voces del Fénix, 32, marzo. Recuperado de https://bit.ly/2u6WtVQ

Shore, C. (2010). La antropología y el estudio de la política pública: reflexiones sobre la "formulación" de las políticas. Antípoda, 10, enero-junio, pp. 21-49, Universidad Los Andes, Colombia.

Sohr, O. y Martínez, L. (2018). \#DebateAborto: chequeos a los argumentos a favor y en contra I y II. Chequeado. Recuperado de http://chequeado.com/el-explicador/debateabortochequeos-a-los-argumentos-a-favor-y-en-contra-de-la-interrupcion-voluntaria-i/

Suppo, S. (2018). Los conflictos que dejará el aborto. La Nación. Recuperado de https://www.lanacion.com.ar/2152649-los-conflictos-que-dejara-el-aborto

Tilly, C. (1984). Les origines du répertoire de l'action collective contemporaine en France et en Grande-Bretagne. Paris: Revued'Histoire.

Vich, V. (2014). Desculturizar la cultura: hacia una nueva generación de Gestores Culturales. En Desculturalizar la cultura. La gestión cultural como forma de acción política (pp. 8198). México: Siglo XXI Editores. 